OPEN ACCESS

Edited by: François Billaut,

Laval University, Canada

Reviewed by:

Martin Burtscher,

University of Innsbruck, Austria

Louise Deldicque,

Catholic University of Louvain,

Belgium

*Correspondence:

Kazushige Goto

kagoto@fc.ritsumei.ac.jp

Specialty section:

This article was submitted to

Exercise Physiology,

a section of the journal

Frontiers in Physiology

Received: 07 February 2020

Accepted: 10 July 2020

Published: 19 August 2020

Citation:

Yatsutani $\mathrm{H}$, Mori $\mathrm{H}$, Ito $\mathrm{H}_{\text {, }}$ Hayashi N, Girard O and Goto K

(2020) Endocrine and Metabolic Responses to Endurance Exercise Under Hot and Hypoxic Conditions.

Front. Physiol. 11:932.

doi: 10.3389/fphys.2020.00932

\section{Endocrine and Metabolic Responses to Endurance Exercise Under Hot and Hypoxic Conditions}

\author{
Haruka Yatsutani ${ }^{1}$, Hisashi Mori' ${ }^{2}$, Hiroto Ito ${ }^{1}$, Nanako Hayashi ${ }^{1}$, Olivier Girard ${ }^{3}$ and \\ Kazushige Goto ${ }^{1 *}$ \\ 'Graduate School of Sport and Health Science, Ritsumeikan University, Kusatsu, Japan, ${ }^{2}$ School of Human Science \\ and Environment, University of Hyogo, Kobe, Japan, ${ }^{3}$ School of Human Sciences (Exercise and Sport Science), \\ The University of Western Australia, Perth, WA, Australia
}

Purpose: We explored the effect of heat stress during an acute endurance exercise session in hypoxia on endocrine and metabolic responses.

Methods: A total of 12 healthy males cycled at a constant workload (60\% of the power output associated with their maximal oxygen uptake under each respective condition) for 60 min in three different environments: exercise under hot and hypoxia $(\mathrm{H}+\mathrm{H}$; fraction of inspiratory oxygen or $\left.\mathrm{FiO}_{2}: 14.5 \%, 32^{\circ} \mathrm{C}\right)$, exercise under hypoxia ( $\mathrm{HYP} ; \mathrm{FiO}_{2}: 14.5 \%$, $23^{\circ} \mathrm{C}$ ), and exercise under normoxia (NOR; $\mathrm{FiO}_{2}: 20.9 \%, 23^{\circ} \mathrm{C}$ ). After completing the exercise, participants remained in the chamber for $3 \mathrm{~h}$ to evaluate metabolic and endocrine responses under each environment. Changes in muscle oxygenation (only during exercise), blood variables, arterial oxygen saturation, and muscle temperature were determined up to $3 \mathrm{~h}$ after exercise.

Results: Serum erythropoietin (EPO) level was increased to similar levels in both $\mathrm{H}+\mathrm{H}$ and HYP at $3 \mathrm{~h}$ after exercise compared with before exercise $(P<0.05)$, whereas no significant increase was found under NOR. No significant difference between $\mathrm{H}+\mathrm{H}$ and HYP was observed in the serum EPO level, blood lactate level, or muscle oxygenation at any time $(P>0.05)$. Exercise-induced serum growth hormone $(\mathrm{GH})$ elevation was significantly greater in $\mathrm{H}+\mathrm{H}$ compared with HYP $(P<0.05)$ and HYP showed significantly lower value than NOR $(P<0.05)$. Arterial oxygen saturation during exercise was significantly lower in $\mathrm{H}+\mathrm{H}$ and $\mathrm{HYP}$ compared with NOR $(P<0.05)$. Furthermore, $\mathrm{H}+\mathrm{H}$ showed higher value compared with $\mathrm{HYP}(P<0.05)$.

Conclusion: The serum EPO level increased significantly with endurance exercise in hypoxia. However, the addition of heat stress during endurance exercise in hypoxia did not augment the EPO response up to $3 \mathrm{~h}$ after completion of exercise. Exercise-induced $\mathrm{GH}$ elevation was significantly augmented when the hot exposure was combined during endurance exercise in hypoxia. Muscle oxygenation levels during endurance 
exercise did not differ significantly among the conditions. These findings suggest that combined hot and hypoxic stresses during endurance exercise caused some modifications of metabolic and endocrine regulations compared with the same exercise in hypoxia.

Keywords: hypoxia, hot, erythropoietin, endurance exercise, muscle oxygenation

\section{INTRODUCTION}

Hypoxic training (i.e., endurance training under normobaric hypoxia) is commonly used by endurance athletes to improve their endurance capacity (Vogt et al., 2001; Dufour et al., 2006). One of the key physiological mechanisms for improved endurance capacity is thought to be hypoxiainduced erythropoiesis, which may lead to improved maximal oxygen uptake $\left(\dot{\mathrm{VO}}_{2} \max \right)$ (Levin, 2002; Millet et al., 2010). Erythropoietin (EPO) is an erythropoietic hormone derived from kidney, and endurance exercise in hypoxia increases EPO production. The increased EPO contributes to augmented red blood cells (Haase, 2013; Turner et al., 2017). The hypoxiainduced increase in hemoglobin $(\mathrm{Hb})$ mass increases the oxygen supply capacity for working muscle, thereby improving endurance capacity (Mairbäurl, 2013).

Many reports have shown a significant EPO response to acute endurance exercise in hypoxia (Schmidt et al., 1991; Mackenzie et al., 2008; Wahl et al., 2013). For example, Wahl et al. (2013) found that endurance exercise (cycling) for $90 \mathrm{~min}$ under both moderate [fraction of inspiratory oxygen $\left(\mathrm{FiO}_{2}\right): 15.9 \%$ ] and severe $\left(\mathrm{FiO}_{2}: 13.2 \%\right)$ hypoxia significantly increased the serum EPO level $3 \mathrm{~h}$ after completion of exercise. Similarly, Mackenzie et al. (2008) showed that $90 \mathrm{~min}$ of rest under hypoxia $\left(\mathrm{FiO}_{2}\right.$ : $14.8 \%$ ) followed by running for $30 \mathrm{~min}$ at $50 \%$ of $\mathrm{V}_{2 \max }$ significantly increased the serum EPO level.

Aside from hypoxia, heat stress during endurance exercise augments hematological variables (Lee et al., 2016). Hot exposure during an acute endurance exercise session decreased endurance performance due to disrupted homeostasis (e.g., a greater increase in core temperature and augmented dehydration) (Cheuvront et al., 2003; Périard et al., 2011). However, it may also increase plasma volume (PV) on the following day after completing the endurance exercise session under hot conditions (Nielsen et al., 1993; Lorenzo et al., 2010). Additionally, endurance exercise under hot condition may upregulate EPO production. Although the effect of acute endurance exercise under hot condition on EPO production remains unclear, 10 consecutive days of endurance training at $40^{\circ} \mathrm{C}(90 \mathrm{~min}$ of cycling/session) significantly increased the serum EPO level (compared with the baseline level before commencing intervention), and additional hypoxic exposure at night ( $8 \mathrm{~h} /$ day) did not cause any further increase (Rendell et al., 2017). Currently, exercise-induced EPO responses to a combination of hypoxic and heat stressors during acute endurance exercise have not been explored.

Therefore, the purpose of the present study was to compare endocrine (in particular the EPO) and metabolic responses to submaximal constant-intensity cycling exercise under (1) hot and hypoxia, (2) hypoxia, and (3) normoxia. We hypothesized that exercise-induced EPO production would be augmented when hot and hypoxia were combined.

\section{MATERIALS AND METHODS}

\section{Participants}

A total of 12 healthy physically active men [mean \pm standard error (SE) age, height, and body weight were $21.5 \pm 0.3$ years, $168.1 \pm 1.2 \mathrm{~cm}$, and $63.6 \pm 2.0 \mathrm{~kg}$, respectively] volunteered for this study. All participants were born and living near sea level. They were informed of the experimental procedures and possible risks associated with this study before they provided written consent. The present study was approved by the Ethics Committee for Human Experiments at Ritsumeikan University, Japan.

\section{Experimental Overview}

All participants visited the laboratory on six occasions. During the initial three visits, they completed an incremental pedaling test on a cycle ergometer (Aerobike 75XLIII; Konami Corporation, Tokyo, Japan) under either hot and hypoxia $(\mathrm{H}+\mathrm{H}$; $\mathrm{FiO}_{2}: 14.5 \%, 32^{\circ} \mathrm{C}$ ), normobaric hypoxia ( $\mathrm{HYP} ; \mathrm{F}_{\mathrm{i}} \mathrm{O}_{2}: 14.5 \%$, $23^{\circ} \mathrm{C}$ ), or normoxia (NOR; $\mathrm{F}_{\mathrm{i}} \mathrm{O}_{2}: 20.9 \%, 23^{\circ} \mathrm{C}$ ) to evaluate $\mathrm{VO}_{2 \text { max }}$. The order of each condition was randomized, and each test was performed at least 2 days apart. The test began at $50 \mathrm{~W}$, and the load was progressively increased by $30 \mathrm{~W}$ every $2 \mathrm{~min}$. Exercise was terminated when the participant remained below $70 \mathrm{rpm}$ for $>5 \mathrm{~s}$ (exhaustion). Respiratory gases were collected and analyzed using an automatic gas analyzer (AE300S; Minato Medical Science Co., Ltd., Tokyo, Japan). The data collected were averaged every $30 \mathrm{~s}$. The highest $\mathrm{V}_{2}$ during exercise was defined as the $\dot{\mathrm{VO}}_{2 \max }$.

The three main experimental conditions (visits 4-6) involved cycling for $60 \mathrm{~min}$ at $60 \%$ of $\dot{\mathrm{VO}}_{2 \max }$ under each condition $(\mathrm{H}+\mathrm{H}, \mathrm{HYP}$, and NOR). The order of each condition was randomized, and each condition was conducted at least 5 days apart. All conditions were completed in an environmental chamber $\left(14.8 \mathrm{~m}^{2}\right)$, and hypoxic exposure was simulated by increasing the nitrogen level in the room (Morishima et al., 2014; Kasai et al., 2017). Venous blood samples were collected before exercise, 20, 40, and $60 \mathrm{~min}$ after commencing exercise, and $3 \mathrm{~h}$ after completing exercise to evaluate the serum EPO and growth hormone $(\mathrm{GH})$ levels, blood lactate, glucose, Hb levels, hematocrit $(\mathrm{Hct})$ value, partial pressure of oxygen $\left(\mathrm{pO}_{2}\right)$, partial pressure of carbon dioxide $\left(\mathrm{pCO}_{2}\right), \mathrm{pH}$, and bicarbonate iron $\left(\mathrm{HCO}_{3}{ }^{-}\right)$levels. 


\section{Experimental Conditions}

Exercise (Aerobike 75XLIII; Konami Corporation, Tokyo, Japan) was commenced following $30 \mathrm{~min}$ of rest after entering the chamber and obtaining baseline measurements. After completing the exercise, participants remained in the chamber for $3 \mathrm{~h}$ to evaluate metabolic and endocrine responses during the post-exercise period. The total duration of each session was approximately $4.5 \mathrm{~h}$ (including rest for $30 \mathrm{~min}$, exercise for $60 \mathrm{~min}$, and rest for $3 \mathrm{~h}$ post-exercise).

During all conditions, the $\mathrm{FiO}_{2}$ level was not displayed to the participant. Water intake ( $2 \mathrm{ml} /$ body weight) was allowed before exercise and at 20 and $40 \mathrm{~min}$ during exercise. During the $3 \mathrm{~h}$ post-exercise period, participants consumed at least $600 \mathrm{ml}$ water, and this volume was matched among the three conditions.

\section{Measurements}

\section{$\mathrm{SpO}_{2}$ and Heart Rate (HR)}

Arterial oxygen saturation $\left(\mathrm{SpO}_{2}\right)$ was recorded continuously (every $1 \mathrm{~s}$ ) using a finger pulse oximeter (PULSOX-Me300; Teijin Pharma Ltd., Tokyo, Japan). HR was recorded continuously during exercise (every $5 \mathrm{~s}$ ) and at $3 \mathrm{~h}$ post-exercise using a wireless HR monitor (RCX5; Polar Electro, Tokyo, Japan). $\mathrm{SpO}_{2}$ and $\mathrm{HR}$ values were averaged every 10 min during exercise and every 30 min during the post-exercise period.

\section{Muscle and Skin Temperatures}

Vastus lateralis muscle and skin temperatures were measured continuously (at a distance of $50 \%$ between the greater trochanter and lateral condyle of the femur) before (after entering the chamber) and during exercise and at $3 \mathrm{~h}$ post-exercise. Muscle temperature was evaluated non-invasively (every $2 \mathrm{~s}$ ) using a probe-type thermometer (Core temp CM-210; TERMO Co., Ltd., Tokyo, Japan) (Wakabayashi et al., 2018). Skin temperature was monitored (every $1 \mathrm{~s}$ ) using a probe-type thermometer and logger (NT Logger N543; Nikkiso-Therm Co., Ltd., Tokyo, Japan) (Maruyama et al., 2019). Muscle and skin temperatures were averaged every 10 min during exercise and every 30 min during the post-exercise period.

\section{Blood Variables}

Following an overnight fast, the participants arrived at the laboratory in the morning $(8: 00 \mathrm{am})$. After $30 \mathrm{~min}$ of rest, baseline blood samples were collected from an inserted cannula in the antecubital vein. Afterward, blood samples were further collected at 20, 40, and $60 \mathrm{~min}$ after commencing exercise and at $3 \mathrm{~h}$ after completing the exercise. To obtain serum, the blood samples were centrifuged for $10 \mathrm{~min}$ at $4^{\circ} \mathrm{C}(3000 \mathrm{rpm})$ and stored at $-80^{\circ} \mathrm{C}$ prior to analysis. Serum EPO and GH levels were measured in a clinical laboratory (SRL Inc., Tokyo, Japan) using an atomic absorption method (for EPO) and radioimmunoassay (for GH). The intra-assay coefficients of variation were $7.2 \%$ for EPO and $3.5 \%$ for $\mathrm{GH}$, respectively.

Whole blood samples were also used to determine the blood $\mathrm{Hb}$ level, $\mathrm{Hct}$ value, $\mathrm{pO}_{2}, \mathrm{pCO}_{2}, \mathrm{pH}$, and $\mathrm{HCO}_{3}{ }^{-}$levels using a blood gas analyzer (OPTI CCA-TS2; Sysmex Corporation, Hyogo, Japan). Exercise-induced changes in PV were calculated using the $\mathrm{Hb}$ level and Hct value, as described previously (Dill and Costill, 1974).

Blood glucose and lactate levels were measured every $20 \mathrm{~min}$ during exercise and at $3 \mathrm{~h}$ after completing the exercise using a glucose analyzer (Freestyle; Nipro Co., Osaka, Japan) and lactate analyzer (Lactate Pro; Arkray Inc., Kyoto, Japan), respectively.

\section{Muscle Oxygenation Evaluated Using Near-Infrared Spectroscopy (NIRS)}

Before exercise (before and after entering the chamber) and 20, 40 , and 60 min after commencing exercise, the oxygenated $\mathrm{Hb}$ (oxy- $\mathrm{Hb}$ ), deoxygenated $\mathrm{Hb}$ (deoxy-Hb), total $\mathrm{Hb}$ (total- $\mathrm{Hb}$ ), and tissue oxygen saturation $\left(\mathrm{StO}_{2}\right)$ were recorded from the vastus lateralis muscle (at a distance of $50 \%$ from the greater trochanter and lateral condyle of the femur) using NIRS (Hb14; ASTEM Co., Ltd., Kanagawa, Japan) (Yamaguchi et al., 2019). To determine muscle oxygenation variables, the NIRS probe was placed on the muscle at an inter-optode distance of $30 \mathrm{~mm}$. All signals were recorded at a sampling frequency of $10 \mathrm{~Hz}$. NIRS data during exercise were expressed relative to the baseline value (data collected before entering the chamber), which was determined under normoxic $\left(\mathrm{FiO}_{2}: 20.9 \%\right)$ and normal $\left(23^{\circ} \mathrm{C}\right)$ conditions.

\section{Respiratory Gas Parameters}

Respiratory gas parameters were collected every 20 min during exercise (15-20, 35-40, and 55-60 min during the 60-min exercise period). Oxygen uptake ( $\left.\mathrm{V}_{2}\right)$, carbon dioxide output $\left(\dot{\mathrm{V}} \mathrm{CO}_{2}\right)$, and minute ventilation ( $\left.\dot{\mathrm{V} E}\right)$ were evaluated using an automatic gas analyzer (AE300S; Minato Medical Science Co., Ltd., Tokyo, Japan). The respiratory exchange ratio (RER) was calculated using the $\dot{\mathrm{V}}_{2}$ and $\dot{\mathrm{V}} \mathrm{CO}_{2}$ values. All respiratory values were averaged every $30 \mathrm{~s}$.

\section{Statistical Analysis}

All data are presented as means \pm SE. Two-way repeatedmeasures analysis of variance (ANOVA) was used to investigate the main effects of condition, time, and the interaction between condition and time. When a significant effect was found, the Tukey-Kramer post-hoc test was performed. Absolute workload, average $\mathrm{SpO}_{2}, \mathrm{HR}$, muscle temperature, and skin temperature were compared using one-way ANOVA followed by a post-hoc test. For all tests, a $P$-value $<0.05$ was considered significant. The values of partial eta squared (partial $\eta^{2}$ ) for one-way and twoway repeated-measures ANOVA were calculated to present effect size. The partial $\eta^{2}$ around of around $0.02,0.13$, and 0.26 were considered as "small," "medium," and "large" (Dalton et al., 2017).

\section{RESULTS}

\section{Absolute Workload During $60 \mathrm{~min}$ of Endurance Exercise}

Absolute workload during exercise under each condition was significantly lower in $\mathrm{H}+\mathrm{H}(110 \pm 4 \mathrm{~W})$ and $\mathrm{HYP}(107 \pm 5 \mathrm{~W})$ than in NOR $(136 \pm 4 \mathrm{~W})$. 


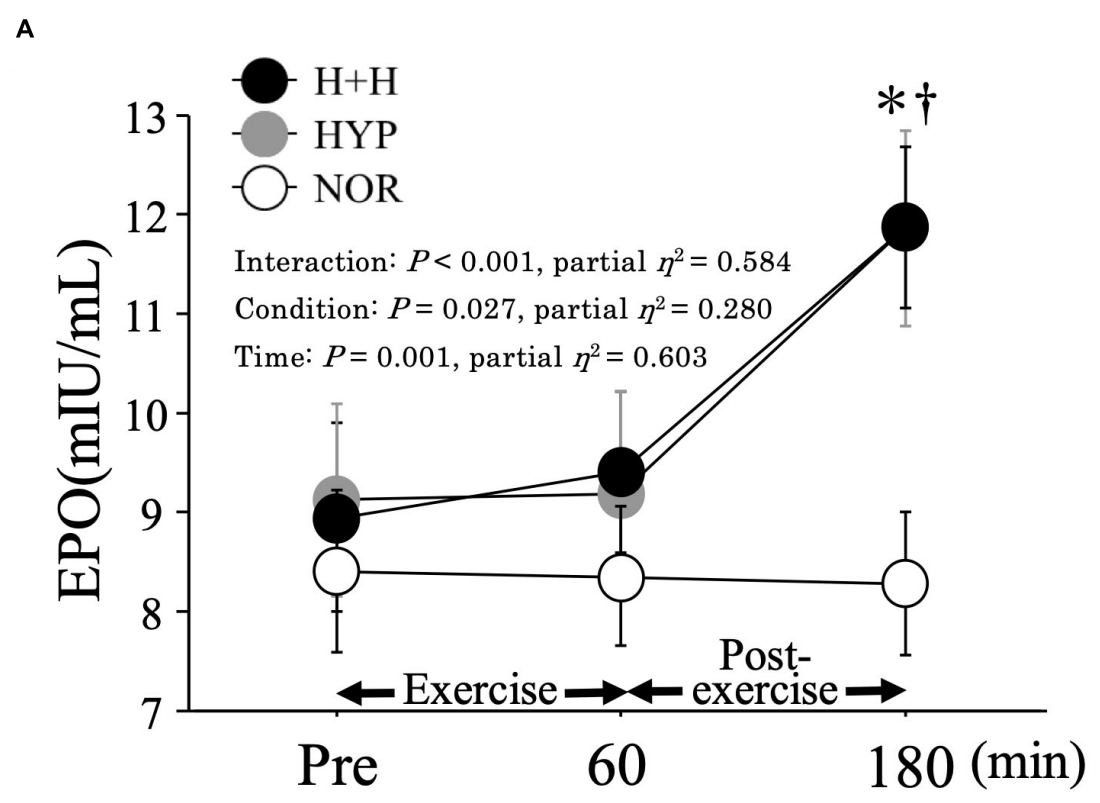

B

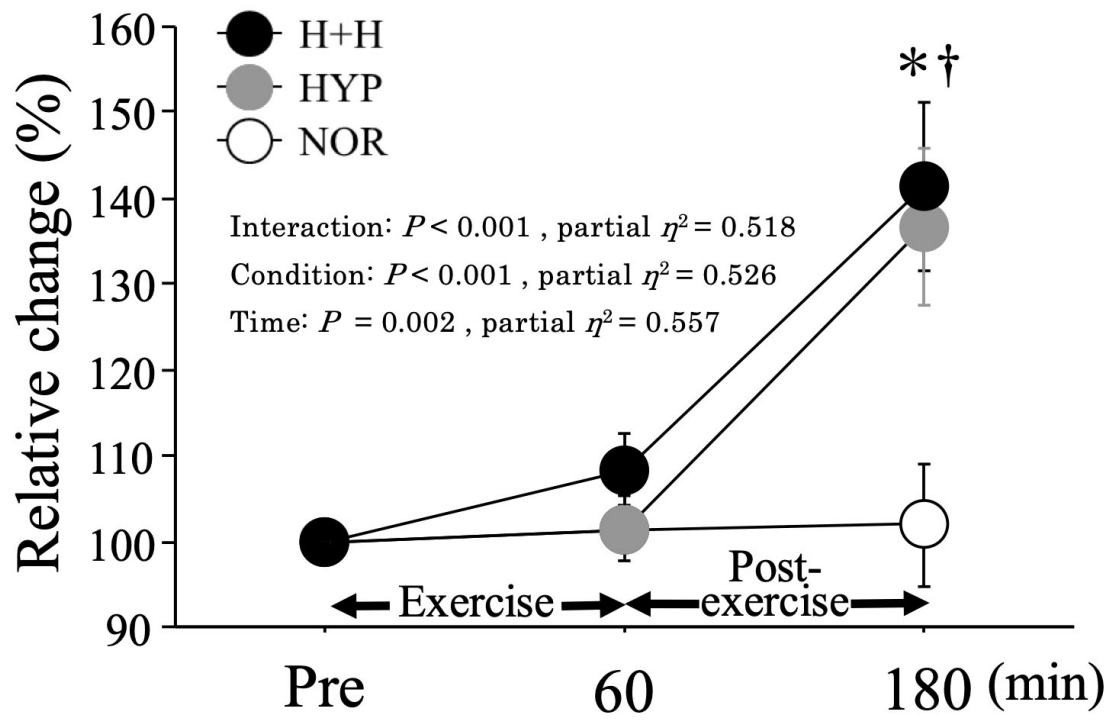

FIGURE 1 | Absolute (A) and relative (B) changes in serum EPO level during exercise and post-exercise. Values are means \pm SE. ${ }^{*} P<0.05$ vs. Pre. ${ }^{\dagger} P<0.05$ vs. NOR.

\section{Serum EPO Level}

Figure 1 presents the absolute (A) and relative (B) changes in the serum EPO level before and after exercise. In both $\mathrm{H}+\mathrm{H}$ and HYP, the serum EPO level was significantly increased at $3 \mathrm{~h}$ after exercise and was significantly higher than that in NOR. However, no significant difference in the serum EPO level was observed between the $\mathrm{H}+\mathrm{H}$ and HYP. The relative change in the EPO level at $3 \mathrm{~h}$ after exercise was significantly higher in both $\mathrm{H}+\mathrm{H}(141.4 \pm 9.9 \%)$ and HYP $(136.7 \pm 9.1 \%)$ than in
NOR (101.9 $\pm 7.1 \%)$, but no significant difference was observed between $\mathrm{H}+\mathrm{H}$ and $\mathrm{HYP}$.

\section{$\mathrm{SpO}_{2}$ and $\mathrm{HR}$}

Figure 2 presents the changes in the $\mathrm{SpO}_{2}$ level from before to after exercise. The average $\mathrm{SpO}_{2}$ during exercise was significantly lower in $\mathrm{H}+\mathrm{H}(86.9 \pm 0.6 \%)$ and HYP $(85.5 \pm 0.6 \%)$ than in NOR (96.1 $\pm 0.3 \%, P<0.01$, partial $\left.\eta^{2}=0.95\right)$. The $\mathrm{SpO}_{2}$ level during exercise was significantly higher in $\mathrm{H}+\mathrm{H}$ than in 


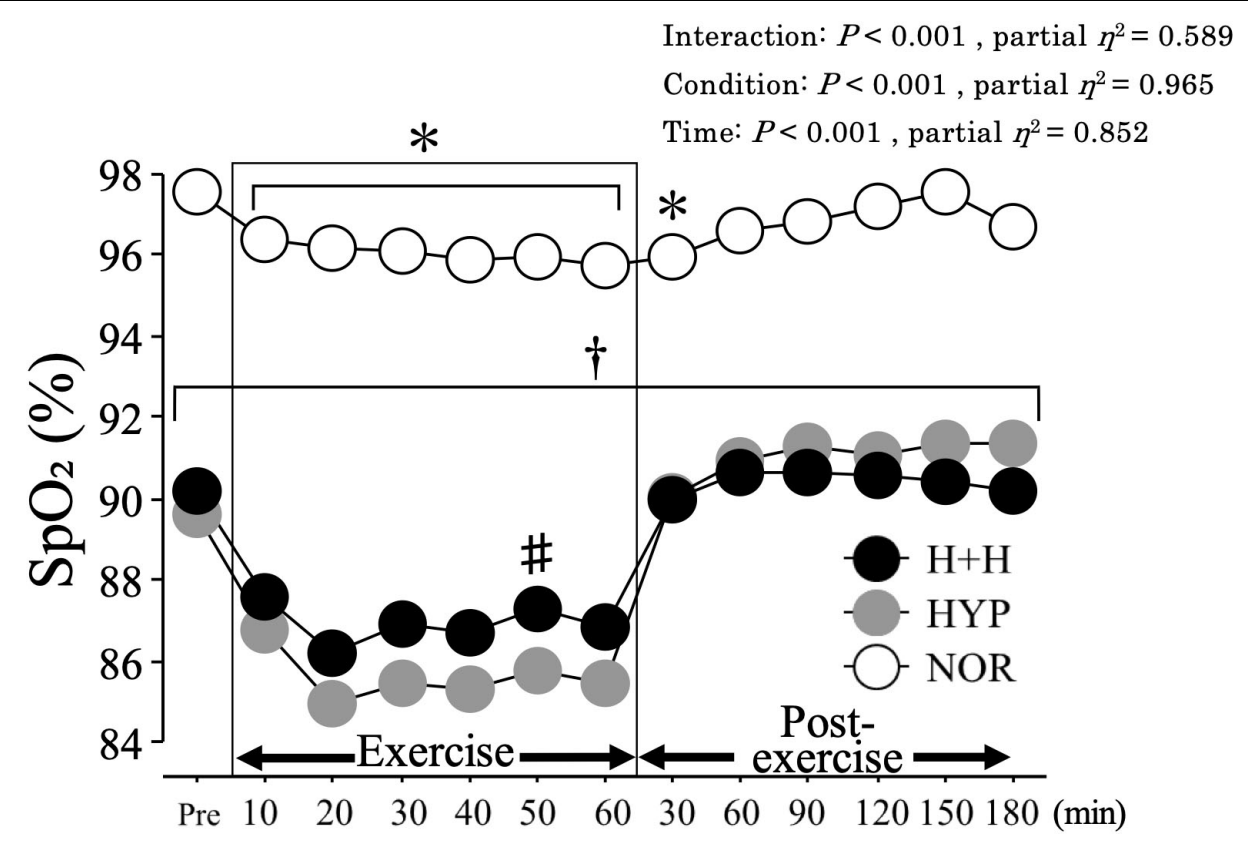

FIGURE $2 \mid \mathrm{SpO}_{2}$ during exercise and post-exercise. Values are means $\pm \mathrm{SE} .{ }^{*} P<0.05$ vs. Pre. ${ }^{\dagger} P<0.05$ vs. NOR. ${ }^{\#} P<0.05$ vs. HYP. Shadow box indicates exercise duration.

HYP at the 50-min time point. During the $3 \mathrm{~h}$ post-exercise period, the average $\mathrm{SpO}_{2}$ remained significantly lower in both $\mathrm{H}+\mathrm{H}(90.4 \pm 0.4 \%)$ and HYP $(91.0 \pm 0.5 \%)$ than in NOR (96.8 $\pm 0.2 \%, P<0.01$, partial $\left.\eta^{2}=0.97\right)$. The average HR during exercise was significantly higher in $\mathrm{H}+\mathrm{H}(152 \pm 3 \mathrm{bpm})$ and NOR $(149 \pm 3 \mathrm{bpm})$ than in HYP $(142 \pm 4 \mathrm{bpm}, P=0.01$, partial $\left.\eta^{2}=0.37\right)$. During the post-exercise period, the average HR was significantly higher in $\mathrm{H}+\mathrm{H}(92 \pm 3 \mathrm{bpm})$ compared with HYP $(78 \pm 3 \mathrm{bpm})$ and NOR $\left(78 \pm 3 \mathrm{bpm}, P<0.01\right.$, partial $\left.\eta^{2}=0.74\right)$.

\section{Muscle and Skin Temperatures}

Figure 3 presents the skin (A) and muscle (B) temperatures before and after exercise. Muscle temperature increased significantly during exercise under all conditions, with a higher average value in $\mathrm{H}+\mathrm{H}\left(37.6 \pm 0.1^{\circ} \mathrm{C}\right)$ than in $\mathrm{HYP}\left(37.1 \pm 0.1^{\circ} \mathrm{C}\right)$ and NOR $\left(37.3 \pm 0.1^{\circ} \mathrm{C}, P<0.01\right.$, partial $\left.\eta^{2}=0.94\right)$. During the post-exercise period, the average muscle temperature was significantly higher in $\mathrm{H}+\mathrm{H}\left(36.8 \pm 0.1^{\circ} \mathrm{C}\right)$ than in $\mathrm{HYP}$ $\left(35.9 \pm 0.1^{\circ} \mathrm{C}\right)$ and NOR $\left(35.8 \pm 0.1^{\circ} \mathrm{C}, P<0.01\right.$, partial $\left.\eta^{2}=0.85\right)$.

Skin temperature increased during exercise, with a significantly higher average value in $\mathrm{H}+\mathrm{H}\left(36.3 \pm 0.2^{\circ} \mathrm{C}\right)$ than in HYP $\left(35.2 \pm 0.1^{\circ} \mathrm{C}\right)$ and NOR $\left(35.5 \pm 0.2^{\circ} \mathrm{C}, P<0.01\right.$, partial $\left.\eta^{2}=0.61\right)$. During the post-exercise period, the average skin temperature remained significantly elevated in $\mathrm{H}+\mathrm{H}$ $\left(35.6 \pm 0.2^{\circ} \mathrm{C}\right)$ compared with HYP $\left(33.7 \pm 0.3^{\circ} \mathrm{C}\right)$ and NOR $\left(33.6 \pm 0.2^{\circ} \mathrm{C}, P<0.01\right.$, partial $\left.\eta^{2}=0.82\right)$.

\section{Blood Variables}

Table 1 presents the blood $\mathrm{pO}_{2}, \mathrm{pCO}_{2}, \mathrm{pH}$, and $\mathrm{HCO}_{3}{ }^{-}$levels. The blood $\mathrm{pO}_{2}$ level during exercise was significantly higher in
NOR than in HYP and $\mathrm{H}+\mathrm{H}$. The blood $\mathrm{pCO}_{2}$ level during exercise and post-exercise was significantly lower in $\mathrm{H}+\mathrm{H}$ than in HYP and NOR. In contrast, the blood $\mathrm{pH}$ levels were significantly higher in $\mathrm{H}+\mathrm{H}$ than in $\mathrm{NOR}$ and $\mathrm{HYP}$. The $\mathrm{HCO}_{3}{ }^{-}$level decreased significantly during exercise, and it was significantly lower in $\mathrm{H}+\mathrm{H}$ than in $\mathrm{HYP}$ and NOR.

Table 2 presents the blood glucose, lactate and $\mathrm{Hb}$ levels, and Hct value and PV. The blood glucose level decreased significantly during exercise, but there was no significant difference among the three condition. The blood lactate level significantly increased during exercise. However, these values did not significantly differ among the three condition.

The blood $\mathrm{Hb}$ level significantly increased during exercise and was significantly lower in $\mathrm{H}+\mathrm{H}$ than in $\mathrm{HYP}$ and NOR at $3 \mathrm{~h}$ after completing exercise. The blood Hct value significantly increased under all conditions, and it was significantly lower in $\mathrm{H}+\mathrm{H}$ than in HYP and NOR at $3 \mathrm{~h}$ after completing exercise. PV significantly decreased during exercise, with no significant difference among the three conditions.

\section{Serum GH}

Figure 4 shows the changes in serum GH level. During $60 \mathrm{~min}$ of exercise, the serum GH level increased significantly during exercise, with higher values in $\mathrm{H}+\mathrm{H}$ and NOR than in HYP.

\section{Muscle Oxygenation}

Figure 5 presents the changes in muscle oxygenation during exercise. The oxy-Hb level during exercise did not differ among the three condition (NOR; $110.3 \pm 6.3 \%$, HYP; $113.5 \pm 10.0 \%$, $\mathrm{H}+\mathrm{H} ; 110.8 \pm 7.2 \% 60 \mathrm{~min}$ during exercise). Moreover, the deoxy-Hb level increased during exercise under all conditions, 

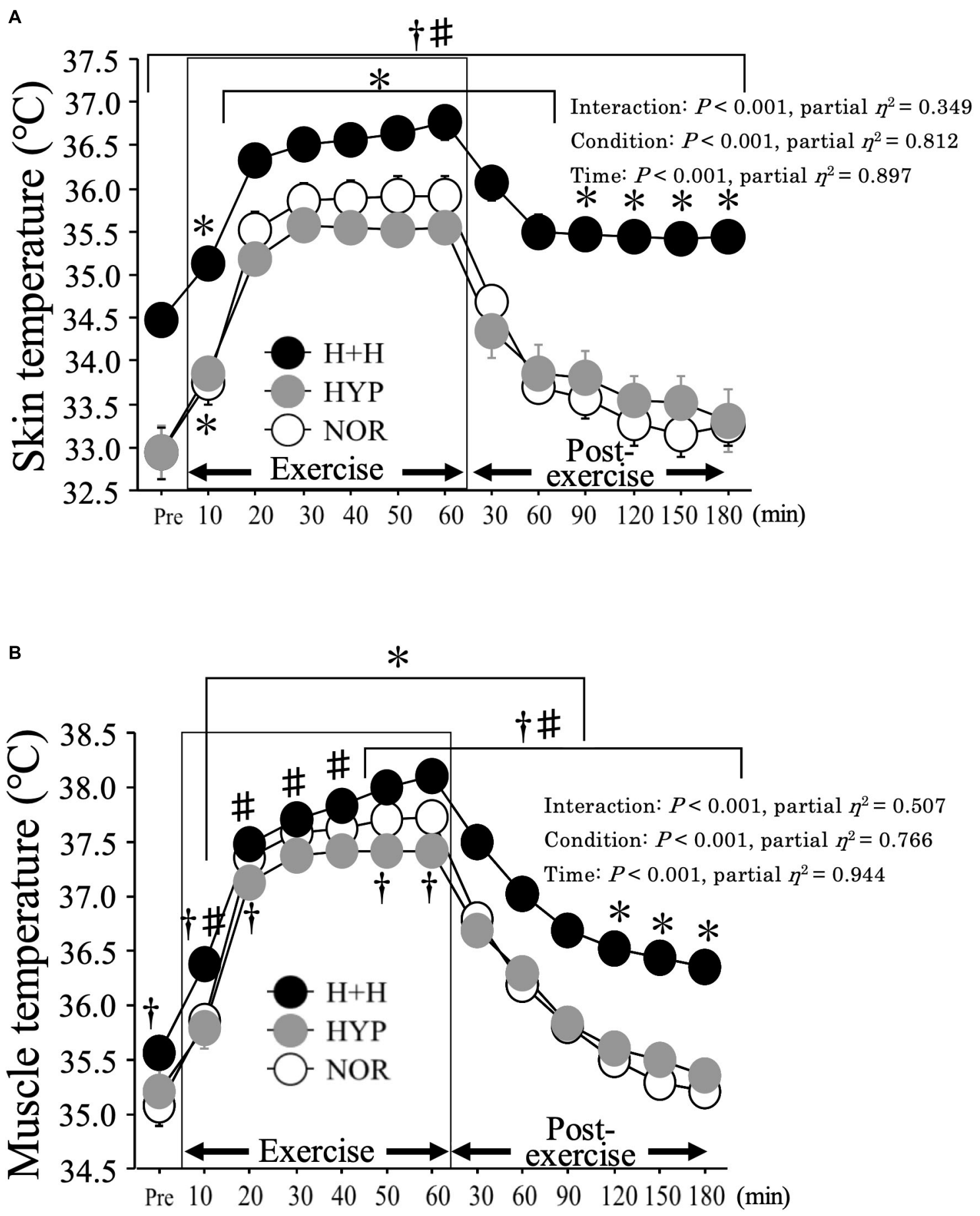

FIGURE 3 | Skin (A) and muscle (B) temperatures during exercise and post-exercise. Values are means \pm SE. ${ }^{*} P<0.05$ vs. Pre. ${ }^{\dagger} P<0.05$ vs. NOR. ${ }^{\#} P<0.05$ vs. HYP. Shadow box indicates exercise duration.

with no significant difference among three conditions (NOR; $182.0 \pm 10.8 \%$, HYP; $190.2 \pm 10.2 \%, \mathrm{H}+\mathrm{H} ; 196.7 \pm 8.6 \%$ 60 min during exercise). The total-Hb level significantly increased during exercise in all conditions, but no significant difference was observed among the three conditions (NOR; $132.3 \pm 6.4 \%$,
HYP; $136.8 \pm 8.5 \%, \mathrm{H}+\mathrm{H} ; 138.5 \pm 6.5 \% 60$ min during exercise). The $\mathrm{StO}_{2}$ decreased significantly during exercise, whereas no significant difference was observed among the three conditions (NOR; $83.2 \pm 2.5 \%$, HYP; $81.2 \pm 3.6 \%, \mathrm{H}+\mathrm{H} ; 78.0 \pm 2.7 \% 60 \mathrm{~min}$ during exercise). 
TABLE 1 | Blood $\mathrm{pO}_{2}, \mathrm{pCO}_{2}, \mathrm{pH}$, and $\mathrm{HCO}_{3}{ }^{-}$levels.

\begin{tabular}{|c|c|c|c|c|c|c|c|c|c|}
\hline & & \multirow[t]{2}{*}{ Pre } & \multirow[t]{2}{*}{$20 \mathrm{~min}$} & \multirow[t]{2}{*}{$40 \mathrm{~min}$} & \multirow[t]{2}{*}{$60 \mathrm{~min}$} & \multirow[t]{2}{*}{ Post $180 \mathrm{~min}$} & \multicolumn{3}{|c|}{ ANOVA (partial $\eta^{2}$ ) } \\
\hline & & & & & & & Interaction & Condition & Time \\
\hline \multirow[t]{3}{*}{$\mathrm{PO} 2(\mathrm{kPa})$} & $\mathrm{H}+\mathrm{H}$ & $7.07 \pm 0.3$ & $7.03 \pm 0.2^{\dagger}$ & $7.01 \pm 0.1^{\dagger}$ & $7.06 \pm 0.2^{\dagger}$ & $6.55 \pm 0.4^{\dagger}$ & $<0.001(0.679)$ & $<0.001(0.746)$ & $<0.001(0.859)$ \\
\hline & HYP & $5.99 \pm 0.4$ & $6.35 \pm 0.2^{\dagger}$ & $6.66 \pm 0.1^{\dagger}$ & $6.44 \pm 0.1^{\dagger}$ & $3.53 \pm 0.2^{\star}$ & & & \\
\hline & NOR & $6.81 \pm 0.7$ & $9.92 \pm 0.5^{\star}$ & $10.04 \pm 0.5^{\star}$ & $9.77 \pm 0.4^{\star}$ & $4.11 \pm 0.4^{\star}$ & & & \\
\hline \multirow[t]{4}{*}{ PCO2 (kPa) } & $\mathrm{H}+\mathrm{H}$ & $5.46 \pm 0.1^{\dagger}$ & $4.96 \pm 0.1^{\dagger}$ & $4.76 \pm 0.1^{\star \dagger}$ & $4.81 \pm 0.2^{\star}$ & $5.18 \pm 0.1^{\dagger}$ & $<0.001(0.445)$ & $<0.001(0.696)$ & $<0.001(0.823)$ \\
\hline & HYP & $5.82 \pm 0.2$ & $5.25 \pm 0.1^{*}$ & $5.01 \pm 0.1^{\star \dagger}$ & $5.04 \pm 0.1^{\star}$ & $6.66 \pm 0.1^{*}$ & & & \\
\hline & NOR & $6.15 \pm 0.2$ & $5.42 \pm 0.1^{\star}$ & $5.27 \pm 0.1^{\star}$ & $5.21 \pm 0.1^{\star}$ & $6.64 \pm 0.2^{*}$ & & & \\
\hline & $\mathrm{H}+\mathrm{H}$ & $7.42 \pm 0.01^{\dagger}$ & $7.42 \pm 0.01^{\dagger}$ & $7.44 \pm 0.01^{\dagger}$ & $7.45 \pm 0.01^{\star \dagger}$ & $7.43 \pm 0.01^{\dagger}$ & $0.001(0.348)$ & $<0.001(0.809)$ & $<0.001(0.705)$ \\
\hline \multirow[t]{2}{*}{$\mathrm{pH}$} & HYP & $7.40 \pm 0.01$ & $7.40 \pm 0.01$ & $7.42 \pm 0.01^{\dagger}$ & $7.44 \pm 0.01^{*}$ & $7.37 \pm 0.01^{\star}$ & & & \\
\hline & NOR & $7.39 \pm 0.01$ & $7.39 \pm 0.01$ & $7.41 \pm 0.01$ & $7.42 \pm 0.01^{*}$ & $7.37 \pm 0.01$ & & & \\
\hline \multirow[t]{3}{*}{$\mathrm{HCO}^{-}(\mathrm{mmol} / \mathrm{L})$} & $\mathrm{H}+\mathrm{H}$ & $25.7 \pm 0.4$ & $23.5 \pm 0.5^{\star}$ & $23.5 \pm 0.5^{\star \dagger}$ & $23.2 \pm 0.3^{\star \dagger}$ & $25.5 \pm 0.4^{\dagger}$ & $0.010(0.261)$ & $0.002(0.441)$ & $<0.001(0.778)$ \\
\hline & HYP & $26.5 \pm 0.5$ & $23.9 \pm 0.4^{\star}$ & $24.0 \pm 0.4^{*}$ & $24.6 \pm 0.4^{\star}$ & $28.3 \pm 0.3^{\star}$ & & & \\
\hline & NOR & $27.2 \pm 0.4$ & $24.0 \pm 0.5^{\star}$ & $24.6 \pm 0.5^{\star}$ & $25.0 \pm 0.5^{\star}$ & $27.9 \pm 0.6$ & & & \\
\hline
\end{tabular}

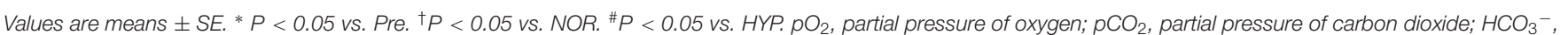
bicarbonate iron.

TABLE 2 | Blood glucose, lactate and $\mathrm{Hb}$ levels, Hct value and $\triangle \mathrm{PV}$.

\begin{tabular}{|c|c|c|c|c|c|c|c|c|c|}
\hline & & \multirow[t]{2}{*}{ Pre } & \multirow[t]{2}{*}{$20 \mathrm{~min}$} & \multirow[t]{2}{*}{$40 \mathrm{~min}$} & \multirow[t]{2}{*}{$60 \mathrm{~min}$} & \multirow[t]{2}{*}{ Post 180 min } & \multicolumn{3}{|c|}{ ANOVA (partial $\eta^{2}$ ) } \\
\hline & & & & & & & Interaction & Condition & Time \\
\hline \multirow[t]{3}{*}{ Glucose (mg/dL) } & $\mathrm{H}+\mathrm{H}$ & $91 \pm 1$ & $84 \pm 1^{*}$ & $84 \pm 1^{*}$ & $86 \pm 2$ & $86 \pm 2$ & $0.162(0.135)$ & $0.055(0.232)$ & $<0.001(0.483)$ \\
\hline & HYP & $89 \pm 2$ & $85 \pm 2$ & $84 \pm 2$ & $83 \pm 2^{*}$ & $85 \pm 2$ & & & \\
\hline & NOR & $88 \pm 2$ & $78 \pm 2^{*}$ & $82 \pm 2^{*}$ & $79 \pm 2^{*}$ & $81 \pm 3^{\star}$ & & & \\
\hline \multirow[t]{3}{*}{ Lactate (mmol/L) } & $\mathrm{H}+\mathrm{H}$ & $1.2 \pm 0.1$ & $3.8 \pm 0.5^{\star}$ & $3.4 \pm 0.5^{\star}$ & $3.0 \pm 0.4^{*}$ & $1.2 \pm 0.1$ & $0.022(0.256)$ & $0.350(0.091)$ & $0.001(0.627)$ \\
\hline & HYP & $1.4 \pm 0.1$ & $3.3 \pm 0.5^{\star}$ & $3.1 \pm 0.5^{\star}$ & $2.6 \pm 0.4^{*}$ & $1.7 \pm 0.1$ & & & \\
\hline & NOR & $1.3 \pm 0.1$ & $3.4 \pm 0.4^{\star}$ & $2.8 \pm 0.5^{\star}$ & $2.5 \pm 0.4^{*}$ & $1.4 \pm 0.1$ & & & \\
\hline \multirow[t]{3}{*}{$\mathrm{Hb}(\mathrm{g} / \mathrm{dL})$} & $\mathrm{H}+\mathrm{H}$ & $14.5 \pm 0.3$ & $15.5 \pm 0.2^{\star}$ & $15.7 \pm 0.2^{\star}$ & $15.7 \pm 0.2^{*}$ & $14.8 \pm 0.2^{\star \dagger}$ & $0.079(0.144)$ & $0.028(0.277)$ & $<0.001(0.842)$ \\
\hline & HYP & $14.8 \pm 0.2$ & $15.8 \pm 0.3^{\star}$ & $15.8 \pm 0.3^{\star}$ & $15.9 \pm 0.3^{\star}$ & $15.5 \pm 0.2^{*}$ & & & \\
\hline & NOR & $14.9 \pm 0.3$ & $15.7 \pm 0.3^{\star}$ & $15.8 \pm 0.3^{\star}$ & $15.8 \pm 0.3^{\star}$ & $15.3 \pm 0.3^{\star}$ & & & \\
\hline \multirow[t]{3}{*}{ Hct (\%) } & $\mathrm{H}+\mathrm{H}$ & $43.4 \pm 0.8$ & $46.6 \pm 0.7^{\star}$ & $47.1 \pm 0.7^{\star}$ & $47.2 \pm 0.6^{\star}$ & $44.5 \pm 0.6^{\star \dagger}$ & $0.069(0.147)$ & $0.036(0.260)$ & $<0.001(0.842)$ \\
\hline & HYP & $44.5 \pm 0.7$ & $47.5 \pm 0.8^{\star}$ & $47.5 \pm 0.8^{\star}$ & $47.7 \pm 0.8^{\star}$ & $46.6 \pm 0.6^{\star}$ & & & \\
\hline & NOR & $44.6 \pm 0.8$ & $47.1 \pm 0.9^{\star}$ & $47.4 \pm 0.9^{\star}$ & $47.5 \pm 0.8^{\star}$ & $46.0 \pm 0.9$ & & & \\
\hline \multirow[t]{3}{*}{$\Delta \mathrm{PV}(\%)$} & $\mathrm{H}+\mathrm{H}$ & 0 & $-11.8 \pm 1.4^{*}$ & $-13.6 \pm 1.0^{*}$ & $-13.9 \pm 1.2^{*}$ & $-4.1 \pm 1.5^{\star}$ & $0.062(0.151)$ & $0.516(0.058)$ & $<0.001(0.848)$ \\
\hline & HYP & 0 & $-11.2 \pm 1.2^{\star}$ & $-11.3 \pm 1.5^{\star}$ & $-12.3 \pm 1.1^{*}$ & $-7.8 \pm 1.4^{\star}$ & & & \\
\hline & NOR & 0 & $-9.3 \pm 1.8^{\star}$ & $-10.7 \pm 1.8^{\star}$ & $-10.8 \pm 2.0^{\star}$ & $-5.2 \pm 2.2$ & & & \\
\hline
\end{tabular}

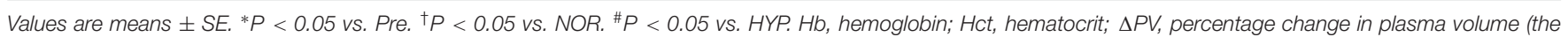
values were expressed in refer to pre-exercise value).

\section{Respiratory Gas Parameters During Exercise}

Table 3 presents the changes in respiratory gas parameters during exercise. $\dot{\mathrm{V}} \mathrm{O}_{2}$ and $\dot{\mathrm{V}} \mathrm{CO}_{2}$ values were significantly lower in $\mathrm{H}+\mathrm{H}$ and HYP than in NOR at all time points. RER was significantly higher in $\mathrm{H}+\mathrm{H}$ and HYP than in NOR at all time points. In terms of $\dot{\mathrm{VE}}$, it was significantly lower in HYP compared with NOR.

\section{DISCUSSION}

The main purpose of the present study was to evaluate the endocrine (in particular EPO) responses to $60 \mathrm{~min}$ of endurance exercise under combined hot and hypoxic condition. We found that both the $\mathrm{H}+\mathrm{H}$ and HYP caused significant increases in the serum EPO level $3 \mathrm{~h}$ after completion of exercise, but no difference was observed between $\mathrm{H}+\mathrm{H}$ and HYP. Moreover, exercise-induced GH elevation was significantly augmented when the hot exposure was combined during exercise in hypoxia. Therefore, additional heat stress during endurance exercise in hypoxia did not affect the erythropoietic response compared with the same exercise under hypoxia alone, but it may be beneficial for increasing $\mathrm{GH}$ response.

Endurance exercise in HYP resulted in a significantly higher serum EPO level compared with NOR at $3 \mathrm{~h}$ after completion of exercise. This observation is consistent with previous studies reporting a $58 \%$ increase after endurance exercise under severe 

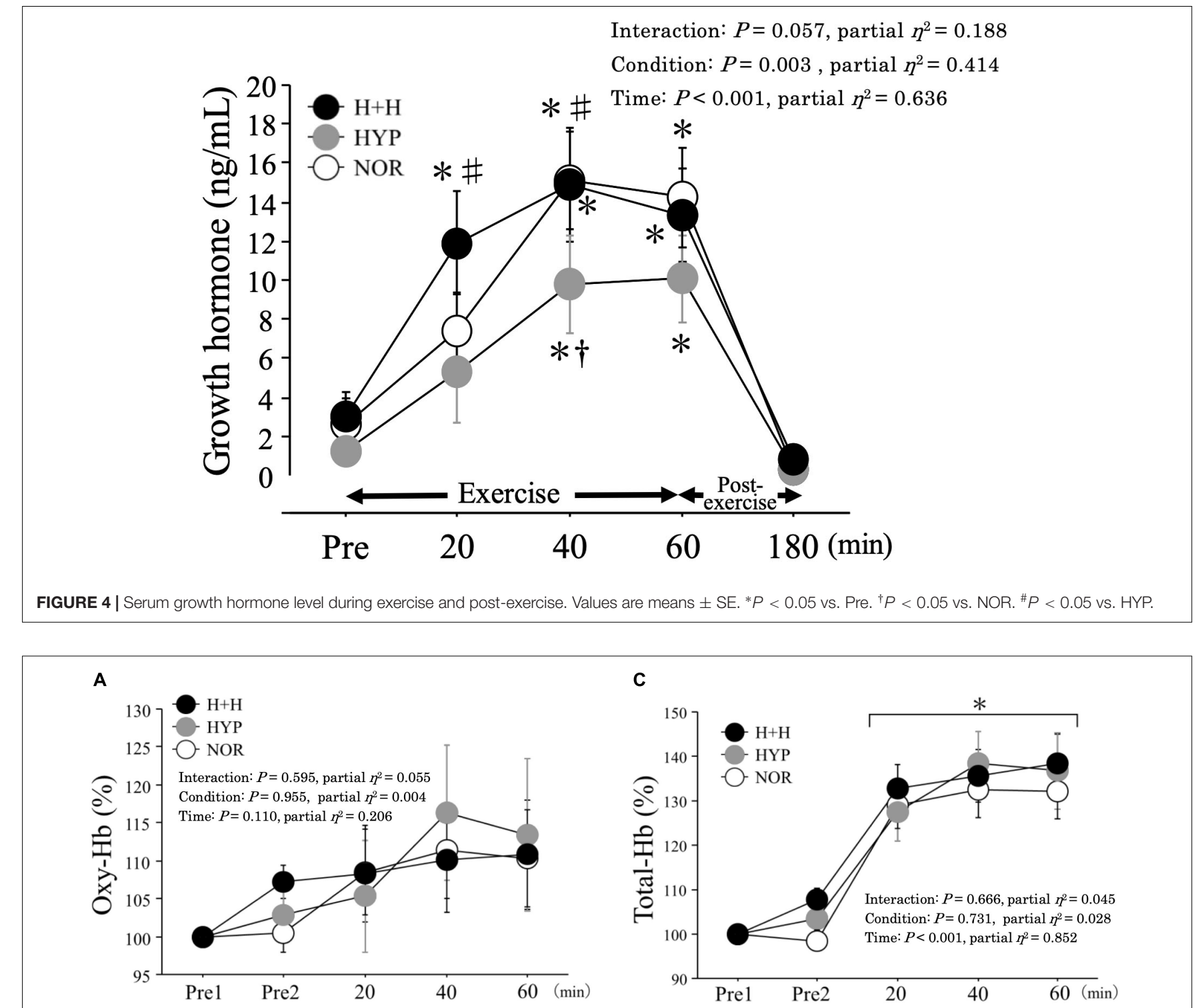

B

D
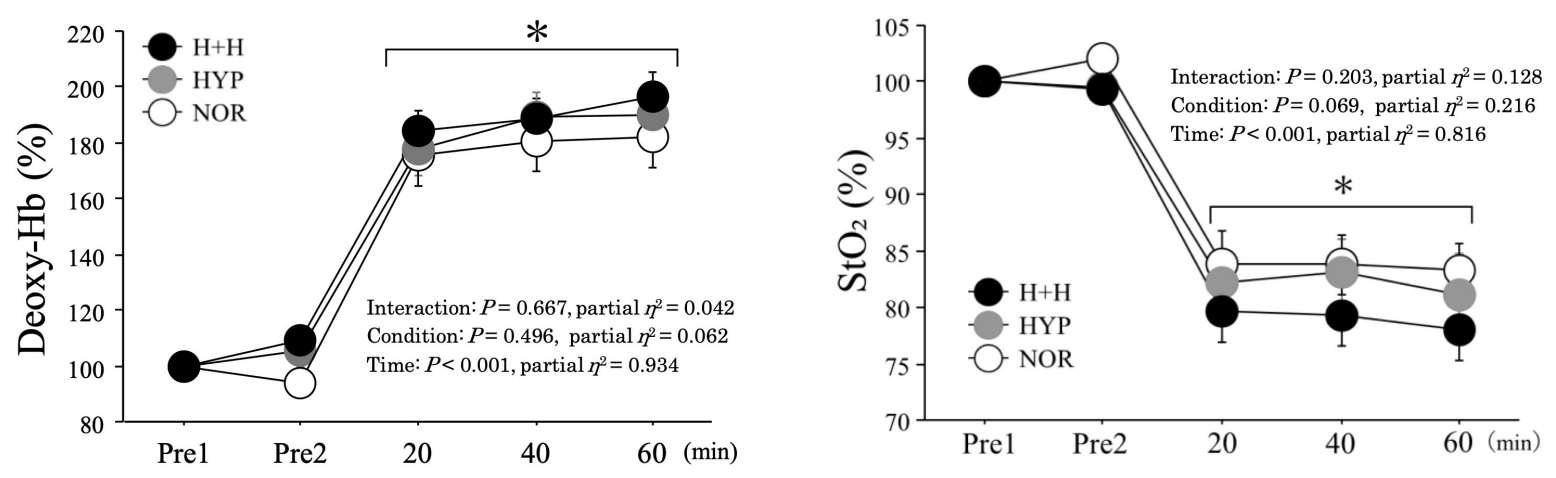

FIGURE 5 | Oxy-hemoglobin (A), deoxy-hemoglobin (B), total-hemoglobin (C), tissue oxygen saturation (D) during exercise. All values were expressed as relative value (values were expressed in refer to pre-exercise value). Pre1 indicates rest under normoxic condition (normal temperature). Pre2 indicates rest under each condition. Values are means \pm SE. ${ }^{P} P<0.05$ vs. Pre1. 
TABLE 3 | Respiratory gas parameters during exercise.

\begin{tabular}{|c|c|c|c|c|c|c|c|}
\hline & & \multirow[t]{2}{*}{$20 \mathrm{~min}$} & \multirow[t]{2}{*}{$40 \mathrm{~min}$} & \multirow[t]{2}{*}{$60 \mathrm{~min}$} & \multicolumn{3}{|c|}{ ANOVA (partial $\eta^{2}$ ) } \\
\hline & & & & & Interaction & Condition & Time \\
\hline \multirow[t]{3}{*}{$\dot{\mathrm{V}} \mathrm{O}^{2}(\mathrm{~mL} / \mathrm{min})$} & $\mathrm{H}+\mathrm{H}$ & $1661 \pm 58^{\dagger}$ & $1720 \pm 61^{\dagger}$ & $1783 \pm 65^{\dagger}$ & $0.208(0.122)$ & $<0.001(0.745)$ & $<0.001(0.914)$ \\
\hline & HYP & $1604 \pm 59^{\dagger}$ & $1652 \pm 66^{\dagger}$ & $1693 \pm 67^{\dagger}$ & & & \\
\hline & NOR & $2006 \pm 57$ & $2068 \pm 59$ & $2145 \pm 55$ & & & \\
\hline \multirow[t]{3}{*}{$\dot{\mathrm{V} C O}{ }^{2}(\mathrm{~mL} / \mathrm{min})$} & $\mathrm{H}+\mathrm{H}$ & $1573 \pm 55^{\dagger}$ & $1580 \pm 55^{\dagger}$ & $1623 \pm 61^{\dagger}$ & $0.405(0.085)$ & $<0.001$ (0.639) & $0.008(0.357)$ \\
\hline & HYP & $1502 \pm 56^{\dagger}$ & $1508 \pm 63^{\dagger}$ & $1516 \pm 62^{\dagger}$ & & & \\
\hline & NOR & $1808 \pm 54$ & $1812 \pm 54$ & $1846 \pm 50$ & & & \\
\hline \multirow[t]{3}{*}{$\dot{V} E(\llcorner/ \min )$} & $\mathrm{H}+\mathrm{H}$ & $53.0 \pm 2.2$ & $56.6 \pm 2.5$ & $61.8 \pm 3.2$ & $0.149(0.140)$ & $0.037(0.304)$ & $<0.001(0.722)$ \\
\hline & HYP & $49.9 \pm 2.2^{\dagger}$ & $53.0 \pm 2.7^{\dagger}$ & $55.4 \pm 3.1^{\dagger}$ & & & \\
\hline & NOR & $56.5 \pm 2.1$ & $59.0 \pm 2.6$ & $62.9 \pm 3.3$ & & & \\
\hline \multirow[t]{3}{*}{ RER } & $\mathrm{H}+\mathrm{H}$ & $0.95 \pm 0.01^{\dagger}$ & $0.92 \pm 0.01^{\dagger}$ & $0.91 \pm 0.01^{\dagger}$ & $0.577(0.062)$ & $<0.001$ (0.539) & $<0.001(0.855)$ \\
\hline & HYP & $0.94 \pm 0.01^{\dagger}$ & $0.91 \pm 0.01^{\dagger}$ & $0.90 \pm 0.01^{\dagger}$ & & & \\
\hline & NOR & $0.90 \pm 0.01$ & $0.88 \pm 0.01$ & $0.86 \pm 0.01$ & & & \\
\hline
\end{tabular}

Values are means $\pm S E .{ }^{\dagger} P<0.05$ vs. $N O R$. $\dot{V} O_{2}$, oxygen uptake; $\dot{V} \mathrm{CO}_{2}$, carbon dioxide output; $\dot{V} E$, minute ventilation; RER, respiratory exchange ratio.

hypoxia $\left(\mathrm{FiO}_{2}: 13.2 \%\right)$, as well as $61 \%\left(\mathrm{FiO}_{2}: 15.9 \%\right)$ and $25 \%$ $\left(\mathrm{FiO}_{2}: 14.8 \%\right)$ increases after endurance exercise under moderate hypoxia (Mackenzie et al., 2008; Wahl et al., 2013). However, we observed that heat stress during endurance exercise under hypoxia did not further increase the EPO response. Another unique observation in our study was that the $\mathrm{SpO}_{2}$ level during endurance exercise was significantly higher in $\mathrm{H}+\mathrm{H}$ than in HYP, despite similar $\mathrm{FiO}_{2}$ (14.5\%). Body temperature and $\dot{\mathrm{V} E}$ were further elevated in $\mathrm{H}+\mathrm{H}$ than in $\mathrm{HYP}$, leading to an increased blood $\mathrm{pO}_{2}$ level. Abbiss et al. (2007) compared blood $\mathrm{pH}$, partial pressure of arterial oxygen, and partial pressure of arterial carbon dioxide levels during prolonged selfpaced cycling under different environmental temperatures (10, 22 , and $\left.34^{\circ} \mathrm{C}\right)$. They observed that hot trial $\left(34^{\circ} \mathrm{C}\right)$ resulted in higher blood $\mathrm{pH}$ and lower partial pressure of arterial carbon dioxide levels compared with cooler trials (10 and $22^{\circ} \mathrm{C}$ ). Elevated blood $\mathrm{pH}$ during endurance exercise in hot would reflect augmented exercise-induced respiratory alkalosis. Similarly, our $\mathrm{H}+\mathrm{H}$ condition induced significantly higher blood $\mathrm{pH}$ with a lower $\mathrm{pCO}_{2}$ level compared with HYP and NOR. Overall, additional hot exposure during endurance exercise in hypoxia would be expected to attenuate the reduction in $\mathrm{SpO}_{2}$. Therefore, combining hot and hypoxia during endurance exercise may not augment EPO production compared with the same endurance exercise under hypoxia alone. However, in the present study, we did not prepare hot alone condition. Therefore, it remains unclear how the heat stress itself affects EPO response.

Both muscle and skin temperatures increased significantly as exercise progressed under all conditions, but these values were significantly higher in $\mathrm{H}+\mathrm{H}$ than in both HYP and NOR. Heat stress was rather modest in the present study $\left(32^{\circ} \mathrm{C}\right)$ compared with previous studies $\left(>35^{\circ} \mathrm{C}\right.$; Hunter et al., 2002; Lorenzo et al., 2010; Guy et al., 2016). However, in $\mathrm{H}+\mathrm{H}$, muscle and skin temperatures reached $38.1 \pm 0.1^{\circ} \mathrm{C}$ and $36.2 \pm 0.2^{\circ} \mathrm{C}$, respectively, by the end of exercise. These levels are comparable with those observed in previous studies, reporting skin temperatures of approximately $35^{\circ} \mathrm{C}$ during exercise under $35^{\circ} \mathrm{C}$ (Bradbury et al., 2019). We also evaluated muscle oxygenation because previous studies reported that lower muscle oxygenation (increased muscle deoxygenation) may aggravate the accumulation of exercise-induced metabolites (Grassi et al., 1999). Moreover, the total-Hb level evaluated by NIRS reflects blood volume in muscles (van Beekvelt et al., 2001; De smet et al., 2017). Considering that heat stress increases blood flow due to vasodilatation (Périard et al., 2015) we hypothesized that exercise-induced increases in total-Hb would be augmented in $\mathrm{H}+\mathrm{H}$. In contrast to our hypothesis, there was no significant difference among the three conditions in either the muscle oxygenation level or total-Hb level. As potential reasons, the absolute workload was significantly lower in both $\mathrm{H}+\mathrm{H}(19 \%)$ and HYP (21\%) compared with NOR due to a significantly lower $\dot{\mathrm{V}}_{2 \max }$. Moreover, augmented skin blood flow during endurance exercise in hot condition may attenuate muscle blood flow (Périard et al., 2013) leading to the lack of increase in total- $\mathrm{Hb}$ in $\mathrm{H}+\mathrm{H}$.

We expected the exercise-induced GH elevation would be increased in both $\mathrm{H}+\mathrm{H}$ and HYP compared with NOR because hypoxia has previously been shown to augment the exerciseinduced GH response (Kon et al., 2010, 2015; Kurobe et al., 2015; Filopoulos et al., 2017). Unexpectedly, exercise-induced GH elevation was significantly lower in HYP compared with NOR due to a lower absolute workload (Felsing et al., 1992). However, $\mathrm{H}+\mathrm{H}$ presented significantly greater $\mathrm{GH}$ elevation than HYP, suggesting the benefit of additional hot stress during endurance exercise in hypoxia.

Several limitations should be considered when interpreting our results. First, we did not implement a hot-alone condition. Therefore, it remains unclear whether heat stress alone affects the EPO response. Second, we did not measure core temperature because we used moderate heat stress $\left(32^{\circ} \mathrm{C}\right)$. Finally, we evaluated the EPO response to endurance exercise until $3 \mathrm{~h}$ after exercise. However, previous studies have shown large interindividual differences in the exercise-induced EPO response (Sinex and Chapman, 2015). Thus, extending measurements during the post-exercise period to beyond $3 \mathrm{~h}$ may be required. 


\section{CONCLUSION}

The serum EPO level significantly increased with endurance exercise under hypoxic conditions. However, the addition of heat stress during endurance exercise in hypoxia did not augment the EPO response at $3 \mathrm{~h}$ after completion of the exercise. Exerciseinduced GH elevation was significantly augmented when the hot exposure was combined during endurance exercise in hypoxia. Muscle oxygenation levels during endurance exercise did not differ significantly among the conditions. These findings suggest that combined hot and hypoxic stresses during endurance exercise caused some modifications of metabolic and endocrine regulations compared with the same exercise in hypoxia.

\section{DATA AVAILABILITY STATEMENT}

All datasets generated for this study are included in the article/supplementary material.

\section{ETHICS STATEMENT}

The present study was approved by the Ethics Committee for Human Experiments at Ritsumeikan University, Japan. The

\section{REFERENCES}

Abbiss, C. R., Nosaka, K., and Laursen, P. B. (2007). Hyperthermic-induced hyperventilation and associated respiratory alkalosis in humans. Eur. J. Appl. Physiol. 100, 63-69. doi: 10.1007/s00421-007-0405-z

Bradbury, K. E., Coffman, K. E., Mitchell, K. M., Luippold, A. J., Fulco, C. S., and Kenefick, R. W. (2019). Separate and combined influences of heat and hypobaric hypoxia on self-paced aerobic exercise performance. J. Appl. Physiol. 127, 513-519. doi: 10.1152/japplphysiol.00023.2019

Cheuvront, S. N., Carter, R., and Sawka, M. N. (2003). Fluid balance and endurance exercise performance. Curr. Sports. Med. Rep. 2, 202-208. doi: 10. 1249/00149619-200308000-00006

Dalton, R. L., Sowinski, R. J., Grubic, T. J., Collins, P. B., Coletta, A. M., Reyes, A. G., et al. (2017). Hematological and hemodynamic responses to acute and short-term creatine nitrate supplementation. Nutrients 9:1359. doi: 10.3390/ nu9121359

De smet, S., Van herpt, P., D’hulst, G., Van thienen, R., Van leemputte, M., and Hespel, P. (2017). Physiological adaptations to hypoxic vs. normoxic training during intermittent living high. Front. Physiol. 8:347. doi: 10.3389/fphys.2017. 00347

Dill, D. B., and Costill, D. L. (1974). Calculation of percentage changes in volumes of blood, plasma, and red cells in dehydration. J. Appl. Physiol. 37, 247-248. doi: 10.1152/jappl.1974.37.2.247

Dufour, S. P., Ponsot, E., Zoll, J., Doutreleau, S., Lonsdorfer-Wolf, E., Geny, B., et al. (2006). Exercise training in normobaric hypoxia in endurance runners. I. Improvement in aerobic performance capacity. J. Appl. Physiol. 100, 1238-1248. doi: 10.1152/japplphysiol.00742.2005

Felsing, N. E., Brasel, J. A., and Cooper, D. M. (1992). Effect of low and high intensity exercise on circulating growth hormone in men. J. Clin. Endocrinol. Metab. 75, 157-162. doi: 10.1210/jcem.75.1.1619005

Filopoulos, D., Cormack, S. J., and Whyte, D. G. (2017). Normobaric hypoxia increases the growth hormone response to maximal resistance exercise in trained men. Eur. J. Sport Sci. 17, 821-829. doi: 10.1080/17461391.2017. 1317834

Grassi, B., Quaresima, V., Marconi, C., Ferrari, M., and Cerretelli, P. (1999). Blood lactate accumulation and muscle deoxygenation during patients/participants provided their written informed consent to participate in this study.

\section{AUTHOR CONTRIBUTIONS}

HY and KG designed the study. HY, HM, HI, and NH performed the material preparation, data collection, and analysis. HY, OG, and KG wrote the first draft of the manuscript. All authors read and approved the final manuscript.

\section{FUNDING}

The present study was funded by the Grant-in-Aid for Scientific Research from the Japan Society for the Promotion of Science.

\section{ACKNOWLEDGMENTS}

We thank all participants who participated in the present study. We would like to acknowledge Kazunobu Okazaki, Ph.D. for the excellent support to the present study.

incremental exercise. J. Appl. Physiol. 87, 348-355. doi: 10.1152/jappl.1999.87. 1.348

Guy, J. H., Pyne, D. B., Deakin, G. B., Miller, C. M., and Edwards, A. M. (2016). Acclimation training improves endurance cycling performance in the heat without inducing endotoxemia. Front. Physiol. 7:318. doi: 10.3389/fphys.2016. 00318

Haase, V. H. (2013). Regulation of erythropoiesis by hypoxia-inducible factors. Blood Rev. 27, 41-53. doi: 10.1016/j.blre.2012.12.003

Hunter, A. M., St clair Gibson, A., Mbambo, Z., Lambert, M. I., and Noakes, T. D. (2002). The effects of heat stress on neuromuscular activity during endurance exercise. Pflugers. Arch. 444, 738-743. doi: 10.1007/s00424-002-0841-x

Kasai, N., Kojima, C., Sumi, D., Takahashi, H., Goto, K., and Suzuki, Y. (2017). Impact of 5 days of sprint training in hypoxia on performance and muscle energy substances. Int J Sports Med. 38, 983-991. doi: 10.1055/s-0043-11 7413

Kon, M., Ikeda, T., Homma, T., Akimoto, T., Suzuki, Y., and Kawahara, T. (2010). Effects of acute hypoxia on metabolic and hormonal responses to resistance exercise. Med. Sci. Sports. Exerc. 42, 1279-1285. doi: 10.1249/MSS. 0b013e3181ce61a5

Kon, M., Nakagaki, K., Ebi, Y., Nishiyama, T., and Russell, A. P. (2015). Hormonal and metabolic responses to repeated cycling sprints under different hypoxic conditions. Growth Horm. IGF Res. 25, 121-126. doi: 10.1016/j.ghir.2015. 03.002

Kurobe, K., Huang, Z., Nishiwaki, M., Yamamoto, M., Kanehisa, H., and Ogita, F. (2015). Effects of resistance training under hypoxic conditions on muscle hypertrophy and strength. Clin. Physiol. Funct. Imaging. 35, 197-202. doi: 10. $1111 /$ cpf.12147

Lee, B. J., Miller, A., James, R. S., and Thake, C. D. (2016). Cross acclimation between heat and hypoxia: heat acclimation improves cellular tolerance and exercise performance in acute normobaric hypoxia. Front. Physiol. 7:78. doi: $10.3389 /$ fphys. 2016.00078

Levin, B. D. (2002). Intermittent hypoxic training: fact and fancy. High Alt. Med. Biol. 3, 177-193. doi: 10.1089/15270290260131911

Lorenzo, S., Halliwill, J. R., Sawka, M. N., and Minson, C. T. (2010). Heat acclimation improves exercise performance. J. Appl. Physiol. 109, 1140-1147. doi: 10.1152/japplphysiol.00495.2010 
Mackenzie, R., Watt, P. W., and Maxwell, N. (2008). Acute normobaric hypoxia stimulates erythropoietin release. High Alt. Med. Biol. 9, 28-37. doi: 10.1089/ ham.2007.1043

Mairbäurl, H. (2013). Red blood cells in sports: effects of exercise and training on oxygen supply by red blood cells. Front. Physiol. 4:332. doi: 10.3389/fphys.2013. 00332

Maruyama, T., Miuzno, S., and Goto, K. (2019). Effects of cold water immersion and wearing compression garment after eccentric exercise on recovery. J. Exerc. Nutrition Biochem. 23, 48-54. doi: 10.20463/jenb.2019. 0007

Millet, G. P., Roels, B., Schmitt, L., Woorons, X., and Richalet, J. P. (2010). Combining hypoxic methods for peak performance. Sports Med. 40, 1-25. doi: 10.2165/11317920-000000000-00000

Morishima, T., Mori, A., Sasaki, H., and Goto, K. (2014). Impact of exercise and moderate hypoxia on glycemic regulation and substrate oxidation pattern. PLoS One 9:e108629. doi: 10.1371/journal.pone.010 8629

Nielsen, B., Hales, J. R., Strange, S., Christensen, N. J., Warberg, J., and Saltin, B. (1993). Human circulatory and thermoregulatory adaptations with heat acclimation and exercise in a hot, dry environment. J. Physiol. 460, 467-485. doi: 10.1113/jphysiol.1993.sp01 9482

Périard, J. D., Cramer, M. N., Chapman, P. G., Caillaud, C., and Thompson, M. W. (2011). Cardiovascular strain impairs prolonged self-paced exercise in the heat. Exp. Physiol. 96, 134-144. doi: 10.1113/expphysiol.2010.05 4213

Périard, J. D., Racinais, S., and Sawka, M. N. (2015). Adaptations and mechanisms of human heat acclimation : applications for competitive athletes and sports. Scand. J. Med. Sci. Sports. 25, 20-38. doi: 10.1111/sms. 12408

Périard, J. D., Thompson, M. W., Caillaud, C., and Quaresima, V. (2013). Influence of heat stress and exercise intensity on vastus lateralis muscle and prefrontal cortex do oxygenation. Eur. J. Appl. Physiol. 113, 211-222. doi: 10.1007/s00421012-2427-4

Rendell, R. A., Prout, J., Costello, J. T., Massey, H. C., Tipton, M. J., Young, J. S., et al. (2017). Effects of 10 days of separate heat and hypoxic exposure on heat acclimation and temperate exercise performance. Am. J. Physiol. Regul. Integr. Comp. Phys. 313, R191-R201. doi: 10.1152/ajpregu.00103. 2017

Schmidt, W., Eckardt, K. U., Hilgendorf, A., Strauch, S., and Bauer, C. (1991). Effects of maximal and submaximal exercise under normoxic and hypoxic conditions on serum erythropoietin level. Int. J. Sports Med. 12, 457-461. doi: 10.1055/s-2007-1024713

Sinex, J. A., and Chapman, R. F. (2015). Hypoxic training methods for improving endurance exercise performance. J. Sport Health Sci. 4, 325-332. doi: 10.1016/j. jshs.2015.07.005

Turner, G., Gibson, O. R., Watt, P. W., Pringle, J. S. M., Richardson, A. J., and Maxwell, N. S. (2017). The time course of endogenous erythropoietin, IL-6, and $\mathrm{TNF} \alpha$ in response to acute hypoxic exposures. Scand. J. Med. Sci. Sports 27, 714-723. doi: 10.1111/sms. 12700

van Beekvelt, M. C., Colier, W. N., Wevers, R. A., and Engelen, B. G. (2001). Performance of near-infrared spectroscopy in measuring local O2 consumption and blood flow in skeletal muscle. J. Appl. Physiol. 90, 511-519. doi: 10.1152/ jappl.2001.90.2.511

Vogt, M., Puntschart, A., Geiser, J., Billeter, R., and Hoppeler, H. (2001). Molecular adaptations in human skeletal muscle to endurance training under simulated hypoxic conditions. J. Appl. Physiol. 91, 173-182. doi: 10.1152/jappl.2001.91.1.173

Wahl, P., Schmidt, A., Demarees, M., Achtzehn, S., Bloch, W., and Mester, J. (2013). Responses of angiogenic growth factors to exercise, to hypoxia and to exercise under hypoxic conditions. Int. J. Sports Med. 34, 95-100. doi: 10.1055/s-00321314815

Wakabayashi, H., Osawa, M., Koga, S., Li, K., Sakaue, H., Sengoku, Y., et al. (2018). Effects of muscle cooling on kinetics of pulmonary oxygen uptake and muscle deoxygenation at the onset of exercise. Physiol. Rep. 6:e13910. doi: 10.14814/ phy2.13910

Yamaguchi, K., Kasai, N., Sumi, D., Yatsutani, H., Girard, O., and Goto, K. (2019). Muscle oxygenation during repeated double-poling sprint exercise in normobaric hypoxia and normoxia. Front. Physiol. 10:743. doi: 10.3389/fphys. 2019.00743

Conflict of Interest: The authors declare that the research was conducted in the absence of any commercial or financial relationships that could be construed as a potential conflict of interest.

Copyright (C) 2020 Yatsutani, Mori, Ito, Hayashi, Girard and Goto. This is an openaccess article distributed under the terms of the Creative Commons Attribution License (CC BY). The use, distribution or reproduction in other forums is permitted, provided the original author(s) and the copyright owner(s) are credited and that the original publication in this journal is cited, in accordance with accepted academic practice. No use, distribution or reproduction is permitted which does not comply with these terms. 